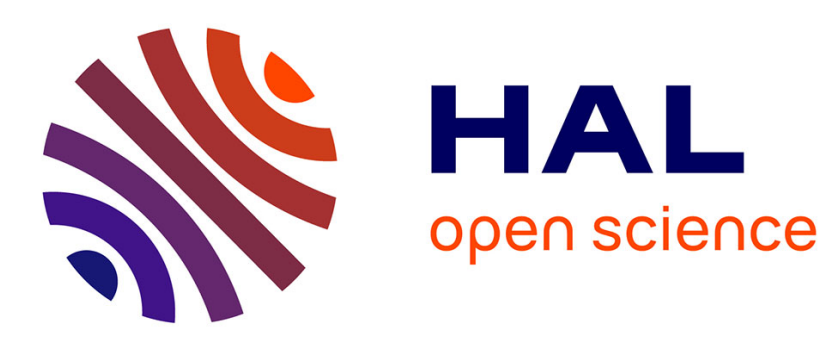

\title{
cis-acting sequences involved in exon selection in the chicken beta-tropomyosin gene.
}

\author{
Maria E. Gallego, Laurent Balvay, Edward Brody
}

\section{To cite this version:}

Maria E. Gallego, Laurent Balvay, Edward Brody. cis-acting sequences involved in exon selection in the chicken beta-tropomyosin gene.. Molecular and Cellular Biology, 1992, 12 (12), pp.5415 - 5425. 10.1128/MCB.12.12.5415 . inserm-01907500

\section{HAL Id: inserm-01907500 https://www.hal.inserm.fr/inserm-01907500}

Submitted on 29 Oct 2018

HAL is a multi-disciplinary open access archive for the deposit and dissemination of scientific research documents, whether they are published or not. The documents may come from teaching and research institutions in France or abroad, or from public or private research centers.
L'archive ouverte pluridisciplinaire HAL, est destinée au dépôt et à la diffusion de documents scientifiques de niveau recherche, publiés ou non, émanant des établissements d'enseignement et de recherche français ou étrangers, des laboratoires publics ou privés. 


\title{
cis-Acting Sequences Involved in Exon Selection in the Chicken $\beta$-Tropomyosin Gene
}

\author{
MARIA E. GALLEGO, ${ }^{1}$ LAURENT BALVAY, ${ }^{2}$ AND EDWARD BRODY ${ }^{1 *}$ \\ Centre de Génétique Moléculaire, Centre National de la Recherche Scientifique, 91190 Gif-sur-Yvette, ${ }^{1}$ \\ and Molecular Biology Department, Pasteur Institute, 75625 Paris, ${ }^{2}$ France
}

Received 4 May 1992/Returned for modification 9 June 1992/Accepted 10 September 1992

\begin{abstract}
The chicken $\beta$-tropomyosin gene contains an internal pair of mutually exclusive exons (6A and 6B) that are selected in a tissue-specific manner. Exon $6 \mathrm{~A}$ is incorporated in fibroblasts and smooth muscle cells, whereas exon $6 \mathrm{~B}$ is skeletal muscle specific. In this study we show that two difierent regions in the intron between the two mutually exclusive exons are important for this specific selection in nonmuscle cells. Sequences in the $3^{\prime}$ end of the intron have a negative effect in the recognition of the $3^{\prime}$ splice site, while sequences in the $5^{\prime}$ end of the intron have a positive efiect in the recognition of the $5^{\prime}$ splice site. First, sequences in exon $6 B$ as well as in the intron upstream of exon $6 \mathrm{~B}$ are both able to inhibit splicing when placed in a heterologous gene. The sequences in the polypyrimidine stretch region contribute to splicing inhibition of exons 5 or $6 \mathrm{~A}$ to $6 \mathrm{~B}$ through a mechanism independent of their implication in the previously described secondary structure around exon 6B. Second, we have identified a sequence of 30 nucleotides in the intron just downstream of exon $6 \mathrm{~A}$ that is essential for the recognition of the $5^{\prime}$ splice site of exon $6 \mathrm{~A}$. This is so even after introduction of a consensus sequence into the $5^{\prime}$ splice site of this exon. Deletion of this sequence blocks splicing of exon 6A to 6B after formation of the presplicing complex. Taken together, these results suggest that both the mutually exclusive behavior and the choice between exons $6 \mathrm{~A}$ and $6 \mathrm{~B}$ of the chicken $\beta$-tropomyosin gene are trans regulated.
\end{abstract}

Alternative splicing is a general mechanism for the regulation of gene expression in eukaryotic cells. The use of alternative splice sites results in the production of different proteins from the same gene, often in a tissue-specific or developmentally regulated pattern $(35,51)$. The relative strengths of $5^{\prime}$ and $3^{\prime}$ splice sites can influence alternative splicing. The strength of a $5^{\prime}$ splice site is defined by its sequence, context, and the proximity to the $3^{\prime}$ splice site $(2$, $14,28,30,39,41,55)$. The strength of a $3^{\prime}$ splice site is defined both by the sequence and location of the branch point and by the length and location of the polypyrimidine tract $(13,16,20,38,40,44,50,53,56)$. Nonetheless, splice sites on either side of alternatively spliced exons ordinarily deviate little from consensus sequences; this implies that other parameters in cis and/or trans are necessary to determine the regulated choice of splice sites.

cis-acting sequences involved in the regulation of splice site choice have been found outside the consensus sequences in the introns $(16,22,32)$ and exons $(5,9,11,18,19$, $32,37,43,48,52$ ) of alternatively spliced pre-mRNAs. Studies on the mechanism of constitutive splicing suggest that differences in the activities or amounts of general splicing factors participate in the regulation of alternative splicing. SF2/ASF is a splicing factor necessary for $5^{\prime}$ splice site cleavage and lariat formation (26) which can also influence the choice of a particular 5' splice site. In general, high concentrations of purified SF2 promote utilization of proximal 5 ' splice sites $(15,25)$.

Regulation of alternative splicing can also be mediated by specialized proteins that control alternative splicing of specific pre-mRNAs. Several trans-acting factors that modulate alternative splicing have recently been identified. The first evidence for the existence of such proteins was provided by

\footnotetext{
* Corresponding author.
}

studies of the hierarchy of alternative splicing in the sex determination pathway of Drosophila melanogaster. Three genes, sex lethal ( $S x l)$, transformer (tra), and transformer 2 (tra-2), encode proteins that modulate splice site selection $(3,4,35)$. Also, the suppressor of the white apricot gene product negatively regulates the splicing of the first two of seven introns in its own pre-mRNA (54). Finally, a 97-kDa protein represses splicing of the third intron of $P$ element transposase in a somatic cell-specific manner (49). These are the only examples in which specific trans-acting proteins have been identified as responsible for tissue- or development-specific regulation of alternative splicing. In vertebrates, studies of a few genes have allowed the identification of sequences implicated in the regulation, but trans-acting factors have not yet been identified.

We have been using the chicken $\beta$-tropomyosin gene as a model system for the study of the mechanisms involved in the tissue-specific regulation of splicing. This gene contains 12 exons of which an internal pair are alternatively spliced in a mutually exclusive fashion (Fig. 1A). Exon 6A is expressed in smooth muscle and nonmuscle cells, while exon $6 \mathrm{~B}$ is skeletal muscle specific (33). Splicing in HeLa cell nuclear extracts of a pre-mRNA that contains exons $6 \mathrm{~A}, 6 \mathrm{~B}$, and 7 produces predominantly the expected mRNA, 6A-7, with a minor product corresponding to the splicing of exon $6 \mathrm{~A}$ to 6B. This minor product results from the use of a branch point located 105 nucleotides (nt) upstream of the $3^{\prime}$ end of the 6A-6B intron. The branch point is followed by a long polypyrimidine stretch (80 nt) (16). A branch point at an unusually long distance from the $3^{\prime}$ splice site is also present in the equivalent intron of the rat $\beta$-tropomyosin pre-mRNA (20). It has been shown that mutations in the polypyrimidine region of intron $6 \mathrm{~A}-6 \mathrm{~B}$ activate the splicing of the intron between exons $6 \mathrm{~A}$ and $6 \mathrm{~B}$ as well as that of the intron between exons 6B and 7 (16). In HeLa cell extracts, inhibition of the splicing between exons $6 B$ and 7 depends on the 


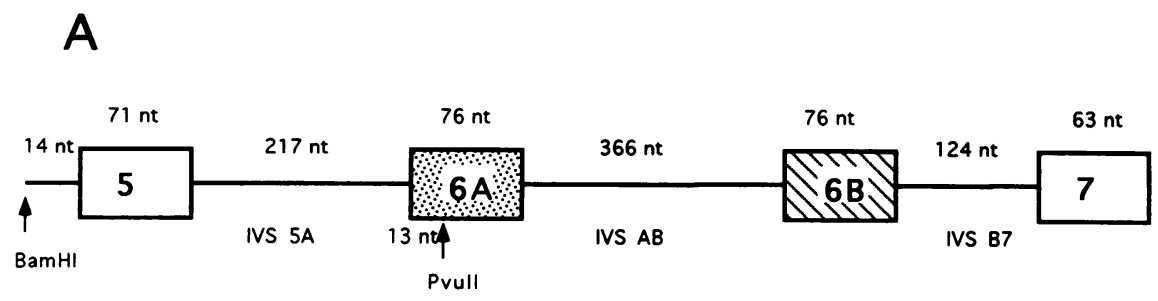

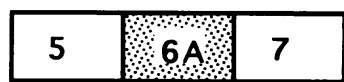

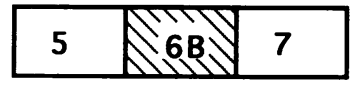

Non-muscle cells Smooth muscle cells

Skeletal muscle cells

B

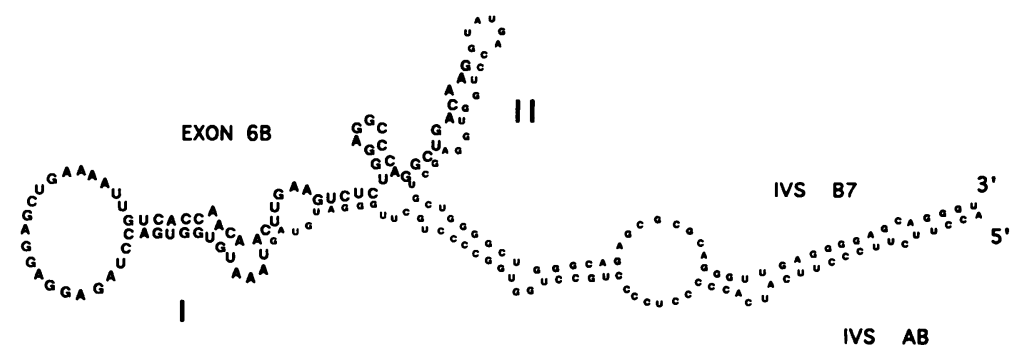

III

FIG. 1. (A) Schematic diagram of the region surrounding the two mutually exclusive exons of the chicken $\beta$-tropomyosin gene. Boxes represent exons, and horizontal lines represent introns. Open boxes represent common exons. The dotted box represents the nonmuscular exon 6A. The striped box represents the skeletal muscle-specific exon 6B. Numbers on top represent the lengths in nucleotides of exons and introns. Positions of the restriction sites used for cloning are shown. (B) Experimentally determined secondary structure around exon 6B (7). The diagram shows exon 6B sequences (in bold), the last $70 \mathrm{nt}$ of intron IVS AB, and the first $60 \mathrm{nt}$ of IVBS7. The stem-loop structures are indicated as I, II, and III.

formation of a specific secondary structure which blocks the utilization of the intron between exons $6 \mathrm{~B}$ and 7 at an early stage of spliceosome formation. This structure involves sequences in exon $6 \mathrm{~B}$ and in the introns upstream and downstream of this exon (Fig. 1B [8]).

We show that both the mutually exclusive behavior and the choice between exons $6 \mathrm{~A}$ and $6 \mathrm{~B}$ of the $\beta$-tropomyosin gene are probably trans regulated. The intron between the two mutually exclusive exons contains elements that are important for the regulation of both exon $6 \mathrm{~A}$ and exon $6 \mathrm{~B}$. First, sequences in exon $6 B$ as well as in the $3^{\prime}$ half of the intron upstream of exon $6 \mathrm{~B}$ are able to inhibit splicing when placed in a heterologous gene. Sequences in the polypyrimidine stretch region contribute to splicing inhibition of exons 5 or $6 \mathrm{~A}$ to $6 \mathrm{~B}$ in nonmuscle cells through a mechanism other than its implication in a previously described secondary structure around exon 6B (8). Second, we have identified a sequence of $30 \mathrm{nt}$ in the intron just downstream of exon $6 \mathrm{~A}$ that is essential for the recognition of the $5^{\prime}$ splice site of exon 6A. This is so even after introduction of a consensus sequence into the $5^{\prime}$ splice site of exon $6 \mathrm{~A}$. Deletion of this sequence inhibits splicing between exons $6 \mathrm{~A}$ and $6 \mathrm{~B}$ after the formation of the presplicing complex.

\section{MATERIALS AND METHODS}

Plasmid constructions. Constructs were prepared by using standard cloning techniques (36) and polymerase chain reaction (PCR) amplification. All $\beta$-tropomyosin clones derived from a 1.7-kb chicken genomic clone spanning exons 4 to 7 (33).

$\beta$-Globin chimeric constructs were from plasmid RR108 containing the human $\beta$-globin first intron and flanking exons (44). The final $6 \mathrm{nt}$ in the intron were changed to a PstI site. All mutants were constructed by PCR amplification of a $\beta$-tropomyosin fragment from $10 \mathrm{nt}$ upstream of the branch point of the intron between exons $6 \mathrm{~A}$ and $6 \mathrm{~B}$ down to the $3^{\prime}$ $A G$ (constructs $G 1, G 4$, and G5) or to $20 \mathrm{nt}$ into exon $6 B$ (G2, G3, and G6) (Fig. 2A and 3). In the case of G3 and G4 the amplified fragment contains mutation p54-2AG (16). The regions of the parental $\beta$-globin construct that were replaced by the PCR-amplified fragments were XhoI-PstI in constructs $\mathrm{G} 1$ and G4, XhoI-AccI in G2 and G3, and HindIIINcoI in G5 and G6.

All of the constructs described below were derived from plasmids pSP65-980, pSP65-700, 700-54, 700-39, and 70054-16 (previously described $[8,16]$ ). pSP65-980 contains a 

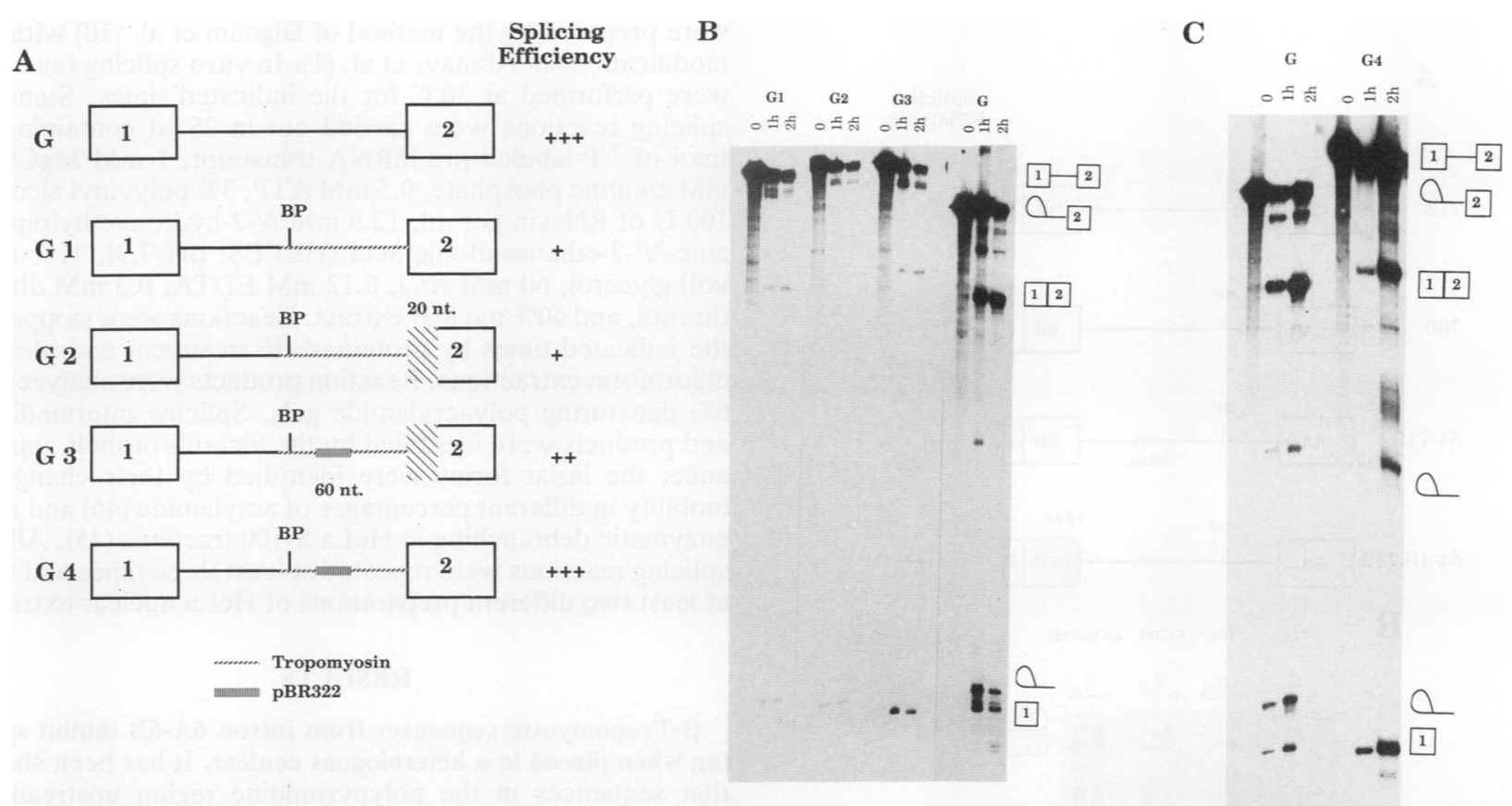

FIG. 2. (A) Diagram of the $\beta$-globin- $\beta$-tropomyosin chimeric constructs. Splicing efficiencies relative to the parent $\beta$-globin pre-mRNA and the positions of the intron sequences that have been replaced with $\beta$-tropomyosin or pBR322 sequences are shown. The striped region in $\beta$-globin exon 2 represents $\beta$-tropomyosin exon 6B sequences. $G$, human $\beta$-globin exons 1 and 2 . G1, the last 52 nt of the $\beta$-globin intron have been substituted by $122 \mathrm{nt}$ of $\beta$-tropomyosin IVS AB sequences, starting $10 \mathrm{nt}$ upstream from the branch point and ending at $\beta$-globin exon 2. G2, the $\beta$-globin intronic sequences are replaced by the $\beta$-tropomyosin sequences as in G1. The first 12 nt of $\beta$-globin exon 2 have been substituted by the first 20 nt of $\beta$-tropomyosin exon 6B. G3 and G4 contain the same substitutions as G2 and G1, respectively. However, in both cases $60 \mathrm{nt}$ in the $\beta$-tropomyosin intronic region, starting $28 \mathrm{nt}$ downstream of the branch point, have been substituted by pBR322 sequences. (B) Sequences in the $\beta$-tropomyosin IVS AB intron as well as in exon $6 \mathrm{~B}$ inhibit splicing when placed in a heterologous gene. In vitro splicing of $\beta$-globin chimeric constructs $\mathrm{G1}, \mathrm{G} 2$, and G3 is described above. In vitro-transcribed RNAs were incubated under splicing conditions for the indicated times. Products of the in vitro reaction were analyzed in a $6 \%$ denaturing acrylamide gel. The structures of the observed bands are indicated. (C) Mutation in the polypyrimidine-rich region of the $\beta$-tropomyosin IVS AB intron restored splicing in the chimeric construct $\mathrm{G} 4$. In vitro splicing of construct $\mathrm{G} 4$, described above, is compared with that of the native $\beta$-globin (G). The splicing reaction conditions are as described in Materials and Methods. The incubation times are indicated. Products of the splicing reaction were analyzed in a $6 \%$ acrylamide denaturing gel. The structures of the various bands are indicated to the right of the autoradiogram.

$\beta$-tropomyosin fragment that starts at a $\mathrm{Bam} \mathrm{HI}$ restriction site in the intron $14 \mathrm{nt}$ upstream of exon 5 and down to a HindIII restriction site lying 41 nt into exon 7. A PvuIIHindIII fragment was used to construct pSP65-700 (the PvuII restriction site lies 13 nt downstream of the start of exon 6A). The 700-54 (16) and 700-39 (8) mutants were produced by site-directed mutagenesis on the PvuII-HindIII fragment cloned into the M13mp18 vector. After mutagenesis, the fragment EcoRI-HindIII was subcloned into the SP65 vector. The double mutant, 700-54-16, was prepared by site-directed mutagenesis on the EcoRI-HindIII fragment from 700-54 cloned into M13mp18; the primer used has been previously described (8). The EcoRI-HindIII fragment after mutagenesis was cloned into the SP65 vector.

The following plasmids were derived from those described above by fusion of exon $6 \mathrm{~B}$ to exon 7 sequences. The deletion of the intron between exons $6 \mathrm{~B}$ and 7 was achieved by replacing the indicated fragments in the parental constructs with a PCR-amplified product, prepared by using a primer containing the sequences of exon $6 \mathrm{~B}$ linked to 10 or $30 \mathrm{nt}$ of exon 7 sequences. 712 and 730 were derived from plasmid SP65-980 by replacing the BstEII-HindIII fragment with the PCR-amplified product and after subcloning the PvuII-HindIII fragment into the pSP72 vector. 54-712 and 39-712 were derived from 700-54 and 700-39, respectively, by replacing the BstEII-HindIII fragment with the PCR-amplified product. 54-16-712 and 6B-54-16 were derived, respectively, from SP65-700 and SP65-980 by replacing the PmacIHindIII fragment with the PCR-amplified product generated by using plasmid 700-54-16 as a template. $6 \mathrm{~B}-\Delta 4,6 \mathrm{~B}-\Delta 6$, $6 \mathrm{~B}-\Delta 10$, and $6 \mathrm{~B}-\Delta 11$ derived from $6 \mathrm{~B}-54-16$ in which the NcoI-PmacI fragment was replaced with the equivalent region from constructs pSV $\Delta 4, \mathrm{pSV} \Delta 6, \mathrm{pSV} \Delta 10$, and pSV $\Delta 11$, respectively (3a). $\Delta 4$ was prepared by cloning the fragment $P v u I I-H i n d I I I$ from $6 \mathrm{~B}-\Delta 4$ into the pSP72 vector. $\Delta 6, \Delta 10$, and $\Delta 11$ were derived from $54-16-712$ by replacing the NcoI-PmacI fragment with the equivalent one from plasmids pSV $\Delta 6, \mathrm{pSV} \Delta 10$, and pSV $\Delta 11$, respectively (3a). $\Delta 6$ is a deletion of $26 \mathrm{nt}$ starting $9 \mathrm{nt}$ downstream of the exon 6 A $5^{\prime}$ splice site. $\Delta 4$ is a deletion of $33 \mathrm{nt}$ starting $37 \mathrm{nt}$ downstream of the exon $6 \mathrm{~A} 5^{\prime}$ splice site. In $\Delta 10,16 \mathrm{nt}$ has been deleted starting 35 nt downstream of the exon 6A 5' splice site. Finally, in $\Delta 1115 \mathrm{nt}$ has been deleted starting 55 nt downstream of the exon 6A 5' splice site. All the mutants were verified by sequencing.

In vitro transcription and pre-mRNA splicing. Uniformly ${ }^{32} \mathrm{P}$-labelled, capped pre-mRNAs were prepared in vitro by using SP6 polymerase as described elsewhere (46). The transcripts were purified by electrophoresis in a $6 \%$ acrylamide-7 M urea sequencing gel. HeLa cell nuclear extracts 


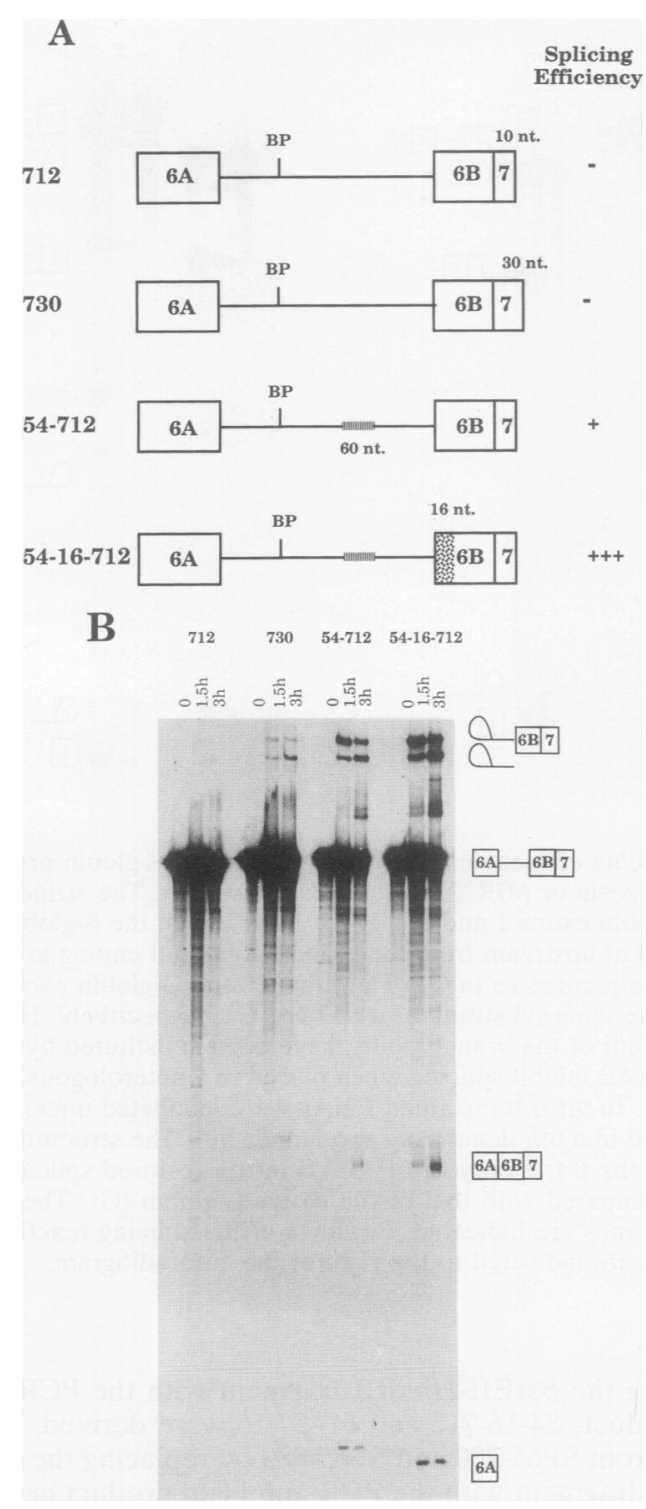

FIG. 3. (A) Diagram of the SP6- $\beta$-tropomyosin DNA templates. Boxes represent exons 6A (nonmuscle and smooth muscle specific) and 6B (muscle specific). The position of the branch point is represented as BP. The number of nucleotides of exon 7 fused to exon 6B is indicated. The length and relative positions of the mutations in the intron and exon $6 \mathrm{~B}$ are shown. The names of the different constructs are on the left side, and their relative splicing efficiencies are on the right. (B) Sequences in the IVS AB intron and in exon 6B are responsible for the inhibition of splicing of exon $6 \mathrm{~A}$ to exon $6 \mathrm{~B}$ in HeLa nuclear extracts. In vitro splicing reactions of the $\beta$-tropomyosin constructs described above were carried out as described in Materials and Methods. The reaction times are indicated; the products were separated in $6 \%$ denaturing polyacrylamide gels. Schematic representations of the products are indicated to the right of the autoradiogram; boxes represent exon sequences and lines represent intron sequences. The products, both linear and lariat, of these precursors have been previously characterized (16). The size of the exon 6A generated after splicing of pre-mRNA 54-712 is $3 \mathrm{nt}$ bigger than that of 54-16-712. This difference in size is due to the difference in polylinker sequence following the SP6 promoter in the two constructs (see Materials and Methods). were prepared by the method of Dignam et al. (10) with the modifications of Abmayr et al. (1). In vitro splicing reactions were performed at $30^{\circ} \mathrm{C}$ for the indicated times. Standard splicing reactions were carried out in $25 \mu$ l containing 30 fmol of ${ }^{32} \mathrm{P}$-labeled pre-mRNA transcript, $1 \mathrm{mM} \mathrm{MgCl}, 20$ $\mathrm{mM}$ creatine phosphate, $0.5 \mathrm{mM}$ ATP, $3 \%$ polyvinyl alcohol, $100 \mathrm{U}$ of RNasin per $\mathrm{ml}, 12.8 \mathrm{mM} \mathrm{N}$-2-hydroxyethylpiperazine- $N^{\prime}$-2-ethanesulfonic acid (HEPES; pH 7.9), $12 \%$ (vol/ vol) glycerol, $60 \mathrm{mM} \mathrm{KCl}, 0.12 \mathrm{mM}$ EDTA, $0.3 \mathrm{mM}$ dithiothreitol, and $60 \%$ nuclear extract. Reactions were stopped at the indicated times by proteinase $\mathbf{K}$ treatment and phenolchloroform extractions. Reaction products were analyzed on $6 \%$ denaturing polyacrylamide gels. Splicing intermediates and products were identified by the kinetics of their appearance; the lariat forms were identified by their change in mobility in different percentages of acrylamide (46) and after enzymatic debranching in HeLa S-100 fractions (45). All the splicing reactions were repeated at least three times and with at least two different preparations of HeLa nuclear extracts.

\section{RESULTS}

B-Tropomyosin sequences from intron 6A-6B inhibit splicing when placed in a heterologous context. It has been shown that sequences in the polypyrimidine region upstream of exon $6 \mathrm{~B}$ are important in the repression of the splicing between exons $6 \mathrm{~A}$ and $6 \mathrm{~B}$ in HeLa cell extracts (16). Furthermore, it has recently been shown that this region participates in the formation of a secondary structure around exon 6B (8). To get further information on the mechanism by which this region inhibits the use of exon $6 \mathrm{~B}$ in the inhibitory HeLa cell extracts, we have introduced intron $6 \mathrm{~A}-6 \mathrm{~B}$ sequences into the intron between exons 1 and 2 of the human $\beta$-globin gene (Fig. 2A). In the first chimeric gene (G1), $50 \mathrm{bp}$ of the intron immediately downstream of $\beta$-globin exon 1 and $6 \mathrm{bp}$ of this same intron upstream of $\beta$-globin exon 2 remain as in the wild-type $\beta$-globin gene. Another construct (Fig. $2 A$, [G2]) extends the replacement in the $3^{\prime}$ direction to include all the distal part of the intron plus the first part of the exon. The first $20 \mathrm{bp}$ of exon $6 \mathrm{~B}$ now replace the first $12 \mathrm{bp}$ of exon 2 of $\beta$-globin. RNAs were transcribed in vitro by using the SP6 RNA polymerase and then spliced in a HeLa nuclear extract. Splicing intermediates and products were detected by standard electrophoresis on polyacrylamide gels. The results are shown in Fig. 2B (G1 and G2). The sizes of the lariat intermediates are bigger than in the $\beta$-globin native gene because $52 \mathrm{nt}$ of the $\beta$-globin intron 1 have been replaced with $122 \mathrm{nt}$ of $\beta$-tropomyosin sequence. Splicing of G2 pre-mRNA yields an mRNA $8 \mathrm{nt}$ longer than the one produced by the $\beta$-globin native gene.

The splicing of these two heterologous RNAs is strongly inhibited compared with the wild-type $\beta$-globin pre-mRNA (Fig. 2B, G1 and G2). Since the substitutions in constructs G1 and G2 do not allow formation of either stem I or stem III in the pre-mRNAs, these experiments suggest that they inhibit the splicing of the intron in which they lie by a separate mechanism unrelated to their capacity to contribute to structures I and III.

We have previously shown that substitution of part of the polypyrimidine stretch, starting $28 \mathrm{nt}$ downstream of the branch point and finishing $18 \mathrm{nt}$ upstream of exon $6 \mathrm{~B}$, with pBR322 sequences stimulates splicing of the 6A-6B intron (16). Therefore, we substituted the same region into construct $\mathrm{G} 1$ to give $\mathrm{G} 4$ and into $\mathrm{G} 2$ to give $\mathrm{G} 3$. In vitro splicing of G4 shows an activation to a level equivalent to that of the wild-type $\beta$-globin pre-mRNA (Fig. 2C, G4). On the other 
hand, G3 pre-mRNA shows only an activation of the first step of the splicing reaction; the second step is absent (Fig. $2 B, G 3)$. These results indicate that sequences in the $5^{\prime}$ end of exon 6B are able to inhibit the second step of splicing in HeLa cell extracts when placed in a heterologous gene.

Inhibition of $\beta$-globin splicing depends entirely on the location of the inhibitory region. Placing the IVS AB (intron between $6 \mathrm{~A}$ and $6 \mathrm{~B}$ ) inhibitory region in front of the $\beta$-globin construct exon 1-intron-exon 2 has no effect on exon 1-exon 2 splicing (data not shown). This is in contrast to the structure-dependent inhibition that this same region imparts to the downstream IVS 6B-7 (8).

Nucleotide substitutions within the intron $6 \mathrm{~A}-6 \mathrm{~B}$ and in the $5^{\prime}$ end of exon $6 \mathrm{~B}$ result in the activation of $6 \mathrm{~A}-6 \mathrm{~B}$ splicing in HeLa cell extracts. We have shown that sequences in the intron upstream of the $\beta$-tropomyosin exon $6 \mathrm{~B}$ as well as in the $5^{\prime}$ end of exon $6 \mathrm{~B}$ have an inhibitory effect when placed in a heterologous gene. We now ask whether replacing these regions is sufficient to activate the homologous reaction, that of splicing exon $6 \mathrm{~A}$ to exon $6 \mathrm{~B}$.

A DNA construct that contains exon $6 \mathrm{~A}$, intron $6 \mathrm{~A}-6 \mathrm{~B}$, and exon $6 \mathrm{~B}$ fused to 10 or $30 \mathrm{nt}$ of exon 7 was made (Fig. $3 \mathrm{~A}, 712$ and 730 ). This is analogous to experiments previously done on the rat $\beta$-tropomyosin gene (21). The results of the splicing reaction are shown in Fig. 3B (712 and 730). No splicing is detected when $10 \mathrm{nt}$ of exon 7 sequences were fused to exon $6 \mathrm{~B}$, and there was very little activation with 30 nt of exon 7. Thus, in agreement with the results with the heterologous $\beta$-globin constructs, the absence of the stem II and III structure is not sufficient to activate the splicing reaction between exons $6 \mathrm{~A}$ and $6 \mathrm{~B}$.

To determine which sequences were sufficient for activation, we substituted pBR322 sequences for the intron sequences that had produced an activation in the heterologous $\beta$-globin constructs. As expected, an activation of the splicing reaction was observed (Fig. 3B, 54-712). To continue the analogy with the heterologous constructs, we introduced both the substitution in the intron upstream of exon $6 \mathrm{~B}$ and a mutation in the $5^{\prime}$ end of exon 6B into 712 (Fig. 3A, 54-16-712). In this construct only the first $16 \mathrm{nt}$ of exon $6 B$ were mutated. The results of the splicing reaction are shown in Fig. 3B, 54-16-712. A further activation of the splicing is produced in this double mutant, as expected from the results for the equivalent $\beta$-globin heterologous construct (G4). We conclude that sequences in the intron between exons $6 \mathrm{~A}$ and $6 \mathrm{~B}$ as well as in the first $16 \mathrm{nt}$ of exon $6 \mathrm{~B}$ are responsible for the inhibition of the splicing of exon $6 \mathrm{~A}$ to exon $6 \mathrm{~B}$ in $\mathrm{HeLa}$ cell extracts by a mechanism other than their implication in a secondary structure around exon $6 \mathrm{~B}$.

To localize more precisely the sequences in intron 6A-6B involved in the inhibition, we made two other mutations. Mutation 18 is a replacement of the last $18 \mathrm{nt}$ of the intron between exons $6 \mathrm{~A}$ and $6 \mathrm{~B}$ by the equivalent sequences from the human $\beta$-globin gene. In mutation 39 , only $14 \mathrm{nt}$ are replaced with a random sequence, starting $13 \mathrm{nt}$ upstream of exon 6B. These constructs were transcribed in vitro, and the RNAs were spliced in HeLa nuclear extracts. Their splicing efficiencies were compared with those of the previously described mutations (Fig. 4). Both mutations are able to produce an activation of the splicing reaction, although to different extents. These results are in agreement with in vivo experiments on the rat $(18)$ and chicken $(31,32) \beta$-tropomyosin genes that show that various mutations introduced into intron 6A-6B $30 \mathrm{nt}$ downstream of the branch point and down to the $3^{\prime}$ splice site are all able to activate the use of exon 6B in nonmuscle cells.

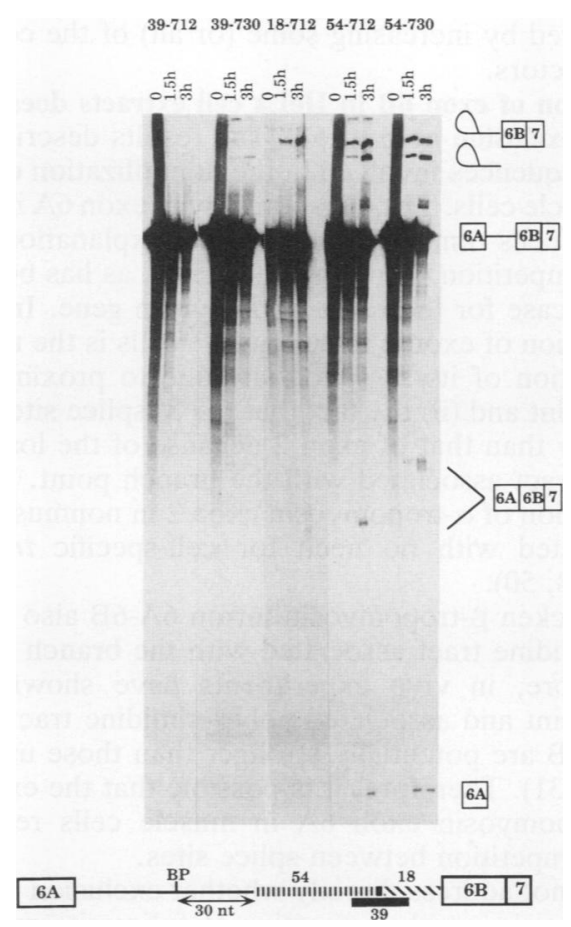

FIG. 4. Different regions in IVS AB play a role in the splicing of exon $6 \mathrm{~A}$ to exon $6 \mathrm{~B}$ in HeLa nuclear extracts. The names of the constructs used as DNA templates for the SP6 polymerase are indicated on the top of the figure. All of them contain exon $6 \mathrm{~A}$, intron IVS $A B$, and exon $6 \mathrm{~B}$ fused to 10 or $30 \mathrm{nt}$ of exon 7 . The different substitutions introduced into the intron are as follows: $39-712$ or $730,14 \mathrm{nt}$ of IVS AB are mutated starting $13 \mathrm{nt}$ upstream of exon $6 B(8) ; 18-712$, the last $18 \mathrm{nt}$ of IVS AB are replaced with the equivalent region from the human $\beta$-globin intron $1 ; 54-712$ or 730 , containing the substitution shown in Fig. 2. The RNAs were spliced in vitro for the indicated times, and the products were separated by electrophoresis on a $6 \%$ denaturing polyacrylamide gel. The structures of the observed bands are indicated. At the bottom of the figure is a diagram of the basic construct with the relative positions of the intronic mutations.

The experiments described above show a striking correlation between the sequences which are responsible for splicing inhibition in the heterologous and homologous constructs. Nonetheless, another set of experiments shows that the two kinds of constructs are not identical. The experiments with the $\beta$-globin pre-mRNAs were carried out by using a HeLa cell nuclear extract which had been prepared by using $0.21 \mathrm{M} \mathrm{NaCl}$ for resuspending HeLa cell nuclei. The $\beta$-tropomyosin pre-mRNA splicing reactions (homologous constructs) were done by using a nuclear extract which had been prepared with $0.30 \mathrm{M} \mathrm{KCl}$ in the nuclear resuspension buffer. This $0.30 \mathrm{M} \mathrm{KCl}$ extract is more active than the $0.21 \mathrm{M} \mathrm{NaCl}$ extract; it supports in vitro splicing at a higher dilution than does the $0.21 \mathrm{M} \mathrm{NaCl}$ extract (data not shown). When we use this extract to measure the splicing efficiency of the $\beta$-globin pre-mRNAs (those used for the data shown in Fig. $2 B$ and $C$ ), the difference in the splicing efficiency between the wild-type pre-mRNA, G, and the mutant premRNAs G1, G2, G3, and G4 diminishes dramatically (data not shown). Thus, the $\beta$-tropomyosin pre-mRNAs contain elements not included in the regions introduced into the $\beta$-globin gene, which contribute to the inhibition of intron $6 \mathrm{~A}-6 \mathrm{~B}$ excision and which are resistant to the partial rever- 
sion effected by increasing some (or all) of the constitutive splicing factors.

Activation of exon 6B in HeLa cell extracts does not allow complete exclusion of exon 6A. The results described above identify sequences involved in the nonutilization of exon $6 \mathrm{~B}$ in nonmuscle cells. The question of why exon $6 \mathrm{~A}$ is excluded in muscle cells remains. One possible explanation could be simple competition between splice sites, as has been shown to be the case for the rat $\alpha$-tropomyosin gene. In this gene the exclusion of exon 2 in nonmuscle cells is the result of (i) the inhibition of its $5^{\prime}$ splice site due to proximity of the branch point and (ii) the fact that the $3^{\prime}$ splice site of exon 3 is stronger than that of exon 2 because of the long polypyrimidine tract associated with the branch point. Therefore, the exclusion of $\alpha$-tropomyosin exon 2 in nonmuscle cells is cis regulated with no need for cell-specific trans-acting factors $(38,50)$.

The chicken $\beta$-tropomyosin intron 6A-6B also has a long polypyrimidine tract associated with the branch point (16). Furthermore, in vivo experiments have shown that the branch point and associated polypyrimidine tract upstream of exon $6 \mathrm{~B}$ are potentially stronger than those upstream of exon $6 \mathrm{~A}$ (31). Therefore, it is possible that the exclusion of the $\beta$-tropomyosin exon $6 \mathrm{~A}$ in muscle cells results from simple competition between splice sites.

We cannot address directly whether exclusion of exon $6 \mathrm{~A}$ in myotubes is merely a question of splice site competition, since in vitro extracts of skeletal muscle cells do not support splicing. Instead, we have activated 6B selection by mutagenesis and asked whether exon 6A was excluded in a HeLa cell extract. An RNA precursor containing $\beta$-tropomyosin exons $5,6 \mathrm{~A}$, and $6 \mathrm{~B}$, together with the mutations able to activate the utilization of exon $6 \mathrm{~B}$, was prepared in vitro and spliced in HeLa nuclear extracts. The results are shown in Fig. 5 (6B-54-16). The three bands migrating more slowly than the pre-mRNA in this $6 \%$ polyacrylamide gel are all lariat RNA products. The most slowly migrating band corresponds to the intermediate lariats resulting from the splicing of exon 5 to exon $6 \mathrm{~A}$ and from the splicing of exon 5 to exon $6 \mathrm{~B}$. The other two bands correspond to the intermediate and final lariats resulting from the splicing of exon $6 \mathrm{~A}$ to exon 6B. A major band at $276 \mathrm{nt}$ corresponds to the mRNA including exons 5, 6A, and 6B (indicated at the right of the autoradiogram in Fig. 5 as 5-6A-6B7). A minor product at $200 \mathrm{nt}$ corresponds to the mRNA resulting from the splicing of exon 5 to exon 6B (indicated in Fig. 5 as 5-6B7). This result indicates that the complete activation of exon $6 \mathrm{~B}$ is not sufficient to produce the exclusion of exon $6 \mathrm{~A}$ in $\mathrm{HeLa}$ cell extracts.

Sequences downstream of the $5^{\prime}$ splice site of exon $6 \mathrm{~A}$ are involved in the exclusion of exon $6 \mathrm{~A}$ when exon $6 \mathrm{~B}$ is active. The results described above suggest that cell-specific transacting factors play a role in the splicing regulation of exon $6 \mathrm{~A}$. A negative factor blocking the 5 ' splice site of intron 6A-6B could be present in muscle cells, or a positive factor able to activate this $5^{\prime}$ splice site could be present in nonmuscle cells. The $5^{\prime}$ splice site of intron $6 \mathrm{~A}-6 \mathrm{~B}$ diverges in 3 bases (GAG/GUACUG) from the consensus sequence,

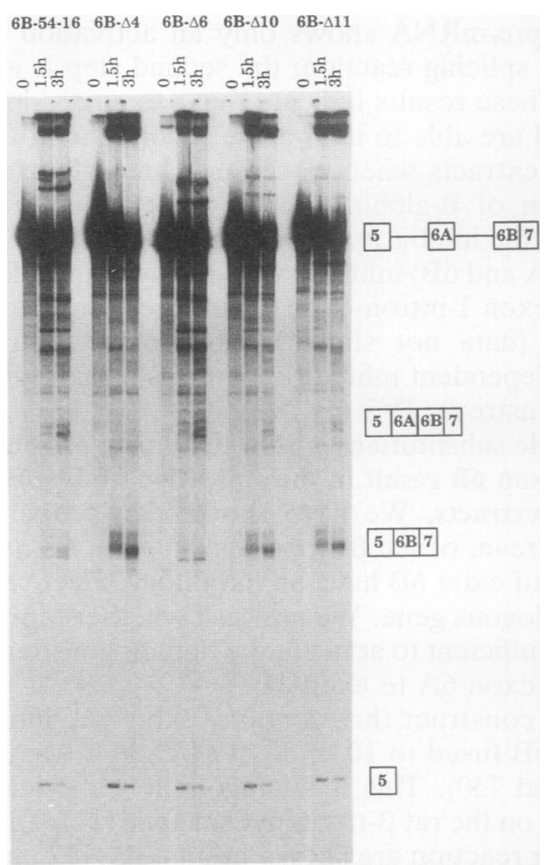

FIG. 5. Activation in HeLa nuclear extracts of exon 6B recognition does not allow exclusion of exon 6A. In vitro splicing reactions were carried out by using RNAs carrying deletions in IVS AB just downstream of the exon 6A 5' splice site. The conditions of the reaction are as indicated in Materials and Methods. The incubation times are shown. The positions of the bands corresponding to the pre-mRNAs, final mRNAs, and first exon are indicated by the corresponding diagrams at the right of the figure. The slowly migrating bands correspond to the lariat intermediates and products. The first two are the lariat intermediates resulting from the splicing of exon 5 to exon $6 \mathrm{~A}$ and of exon 5 to exon $6 \mathrm{~B}$. The other two bands are the intermediate and final lariats resulting from splicing of exon $6 \mathrm{~A}$ to exon $6 \mathrm{~B}$.

which probably makes it a weak splice site (33). If a positive factor were necessary for activating this $5^{\prime}$ splice site in HeLa cells, we should be able to identify sequences needed in cis for the recognition of the exon $6 \mathrm{~A}^{\prime}$ splice site. Deletion mutations were therefore introduced in the 6A-6B intron between the $5^{\prime}$ splice site of exon $6 \mathrm{~A}$ and the branch point.

An 80-nt deletion directly downstream of the $5^{\prime}$ splice site of the intron 6A-6B induces exclusion of exon 6A when introduced into the construct 6B-54-16 (data not shown). Smaller deletions were introduced into this region in an attempt to define more precisely the sequences involved (Fig. 6). Mutation $\Delta 6$ is a deletion of $26 \mathrm{nt}$ starting $9 \mathrm{nt}$ downstream of the $5^{\prime}$ splice site. Mutation $\Delta 4$ deletes $33 \mathrm{nt}$ starting $37 \mathrm{nt}$ downstream of the $5^{\prime}$ splice site. These deletions were introduced into plasmid 6B-54-16, the DNAs were transcribed in vitro, and the pre-mRNAs were spliced in HeLa nuclear extracts. When deletion $\Delta 6$ was introduced, no effect on the splicing reaction (compared with 6B-54-16)

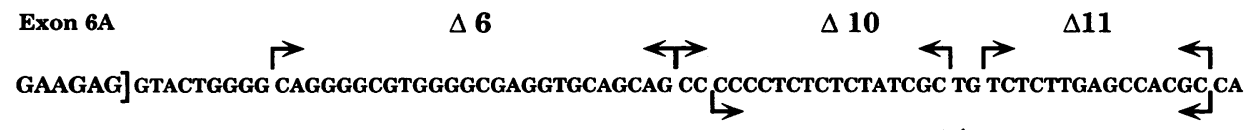

FIG. 6. Nucleotide sequences in IVS AB just downstream of exon 6A. The arrows define the sequences deleted in the different mutants. 
was observed. Very little mRNA in which exon 6A had been excluded was detected (Fig. 5, 6B- $\Delta 6$ ). On the contrary, when deletion $\Delta 4$ was introduced (Fig. $5,6 B-\Delta 4$ ) the only mRNA detected resulted from exon 5 splicing to exon $6 \mathrm{~B}$. No mRNA or lariat RNA which resulted from the splicing of exon $6 \mathrm{~A}$ to exon $6 \mathrm{~B}$ was detected. The fact that deletion $\Delta 6$ had no effect in the splicing reaction shows that the effect of $\Delta 4$ is a consequence of the removal of specific sequences rather than an effect of the distance between downstream sequences and the $5^{\prime}$ splice site following exon $6 \mathrm{~A}$.

To better define the sequences needed for activation of the $5^{\prime}$ splice site of exon $6 \mathrm{~A}$, two other mutants were made. Mutants $\Delta 10$ and $\Delta 11$ correspond respectively to the deletion of the first $16 \mathrm{nt}$ of $\Delta 4$ and the last $13 \mathrm{nt}$ of $\Delta 4$. The results are shown in Fig. 5 (6B- $\Delta 10$ and $6 \mathrm{~B}-\Delta 11)$. In both cases a strong inhibition of the splicing reaction between exons $6 \mathrm{~A}$ and $6 \mathrm{~B}$ is observed, although each is less strong than the effect observed with $\Delta 4$; in the latter, no lariat formation resulting from exon $6 \mathrm{~A}$ splicing to exon $6 \mathrm{~B}$ can be detected. We conclude that the effect of mutation $\Delta 4$ is to weaken the $5^{\prime}$ splice site of exon $6 \mathrm{~A}$, preventing the splicing of exon $6 \mathrm{~A}$ to exon $6 \mathrm{~B}$ when an alternative $5^{\prime}$ splice site can be used (in this case, the one from exon 5). This effect together with the competition between the $3^{\prime}$ splice sites upstream of exons $6 \mathrm{~A}$ and $6 \mathrm{~B}$ allows the exclusion of exon $6 \mathrm{~A}$. Similar results have been obtained by using transfected minigenes in cultured quail myoblasts (3a).

Sequences downstream of exon $6 \mathrm{~A}$ are essential for the recognition of the exon $6 A 5^{\prime}$ splice site. Results in the previous section showed that sequences in the intron downstream of the exon $6 \mathrm{~A}^{\prime}$ ' splice site are important for the recognition of exon $6 \mathrm{~A}$ in nonmuscle cells. The effect of these sequences could be to strengthen the weak $5^{\prime}$ splice site downstream of exon $6 \mathrm{~A}$. It is possible that these sequences are essential for the recognition of the 5 ' splice site of exon $6 \mathrm{~A}$, even in the absence of a competitor $5^{\prime}$ splice site. We have introduced these deletions into a DNA construct that contains only exons $6 \mathrm{~A}$ and $6 \mathrm{~B}$ (54-16-712). As expected from the previous results, $\Delta 6$ has no effect on the splicing reaction (Fig. 7A). Deletion $\Delta 4$ produced almost complete inhibition of the splicing reaction compared with that in the wild-type construct (54-16-712) (Fig. 7A). Deletion $\Delta 10$ (the first $15 \mathrm{nt}$ of $\Delta 4$ ) has no effect in this splicing reaction, even though it must have an effect on the strength of the intron 6A-6B 5' splice site (since in the presence of an alternative $5^{\prime}$ splice site [construct $6 \mathrm{~B}-\Delta 10$ in Fig. 5], the $5^{\prime}$ splice site of exon $6 \mathrm{~A}$ is completely ignored). On the contrary, deletion $\Delta 11$ (deletion of the last $13 \mathrm{nt}$ of $\Delta 4$ ) induces a strong inhibition of the splicing reaction (Fig. 7A), although less strong than the effect of $\Delta 4$.

We next asked whether the sequences defined by $\Delta 4$ were necessary because the $5^{\prime}$ splice site downstream of exon $6 \mathrm{~A}$ is weak, matching the $5^{\prime}$ splice site consensus in only three of six bases (GUA CUG instead of GUA AGU). When we changed this $5^{\prime}$ splice site to the consensus sequence, the splicing reaction was activated (Fig. $7 \mathrm{~B}$, compare $\Delta 4$ and $\Delta 4 \mathrm{C})$, but not to the level of 54-16-712. We conclude that sequences in the intron downstream of the exon 6A 5' splice site are important for its recognition even in the absence of a competing $5^{\prime}$ splice site. When these sequences are deleted, the intron $6 \mathrm{~A}-6 \mathrm{~B} 5^{\prime}$ splice site is completely ignored by the splicing machinery.

The splicing reaction takes place in a complex called the spliceosome $(6,12,17)$. By using native gel electrophoresis, two complexes have been identified during the course of the splicing reaction. The prespliceosome complex A contains
pre-mRNA, U2 small nuclear ribonucleoprotein (snRNP) and U1 snRNP; the mature spliceosome complex B forms after the binding as well of U4, U5, and U6 snRNPs $(23,24$, $27,29,42,47,57)$. We have analyzed complex formation by using $\Delta 4$ pre-mRNA. The results in Fig. 7C show that this mRNA is able to form the presplicing complex A very efficiently, but the mature spliceosome B is not detected. This suggests that the $5^{\prime}$ splice site (and modulating sequences defined by $\Delta 4$ ) continues to participate in spliceosome formation after fixation of $U 1$ and U2 snRNPs. However, we have to point out a lack of correlation of splicing efficiency and the level of B complex. We do not understand why the amount of B complex is lower in 54-16-712 (it is nonetheless clearly there) than in 54-712. Further experiments are in progress to clarify this point.

\section{DISCUSSION}

Elements involved in exon $6 \mathrm{~B}$ exclusion in nonmuscle cells. During development, a number of tissue-specific splicing events are based on alternative, mutually exclusive choices of exons. We have been studying one such event, the choice of either exon $6 \mathrm{~A}$ or exon $6 \mathrm{~B}$ in the chicken $\beta$-tropomyosin pre-mRNA. In skeletal muscle, exon $6 B$ is chosen, whereas in all other tissues exon 6A is included in the mRNA. This splicing behavior is highly conserved in vertebrates. In comparing splicing of the rat $(18)$ and chicken $(31,32)$ pre-mRNAs, one is struck with the similarities of the location of sequences shown to be necessary for the control of this splicing event.

We have used HeLa cell nuclear extracts to examine the in vitro splicing pattern of this region. As expected, exon $6 \mathrm{~B}$ was largely ignored in HeLa cell extracts; it was included as part of a large intron extending from the $5^{\prime}$ splice site of IVS $A B$ (the intron upstream of exon $6 B$ ) to the $3^{\prime}$ splice site of IVS B7 (the intron downstream of exon 6B). We noticed that mutations in IVS AB that stimulated excision of this intron simultaneously stimulated splicing of IVS B7. These stimulatory mutations included the substitution of pBR322 sequences for part of the long pyrimidine stretch found at the $3^{\prime}$ end of IVS AB, between the far upstream branch point $(-105 \mathrm{nt})$ and the terminal AG. We have previously shown in vitro that repression of IVS B7 in nonmuscle cells is related to the formation of a secondary structure around exon $6 \mathrm{~B}$ (8). The folding of the region forms stem I, located at the very beginning of exon 6B; stem II, formed between sequences in the $3^{\prime}$ end of exon $6 \mathrm{~B}$ and the very beginning of the intron between exons 6B and 7; and stem III, derived from base-pairing between the polypyrimidine region upstream of exon 6B and a G-rich region present in the intron 6B-7 (Fig. 1B). In vivo studies by transfection of a minigene construct extending from exons 5 to 7 into nondifferentiated (myoblasts) and differentiated (myotubes) muscle cells have also identified the $5^{\prime}$ half of exon $6 \mathrm{~B}$ and the upstream pyrimidine-rich region as negatively acting cis elements, which prevent splicing of the skeletal muscle-specific exon in myoblasts (32). Moreover, it has been shown that at least part of this negative control depends on the existence of a stem-loop structure involving exon sequences (stem I) (34). Therefore, there is concordance between in vivo and in vitro results concerning the cis elements involved in the regulation as well as the role played by stem $I$ in this negative regulation. However, in vivo mutagenesis analysis affecting stems II and III does not support their role in the inhibition of exon $6 \mathrm{~B}$ use in myoblasts. These results suggest that the negative elements in the polypyrimidine region upstream of 
A

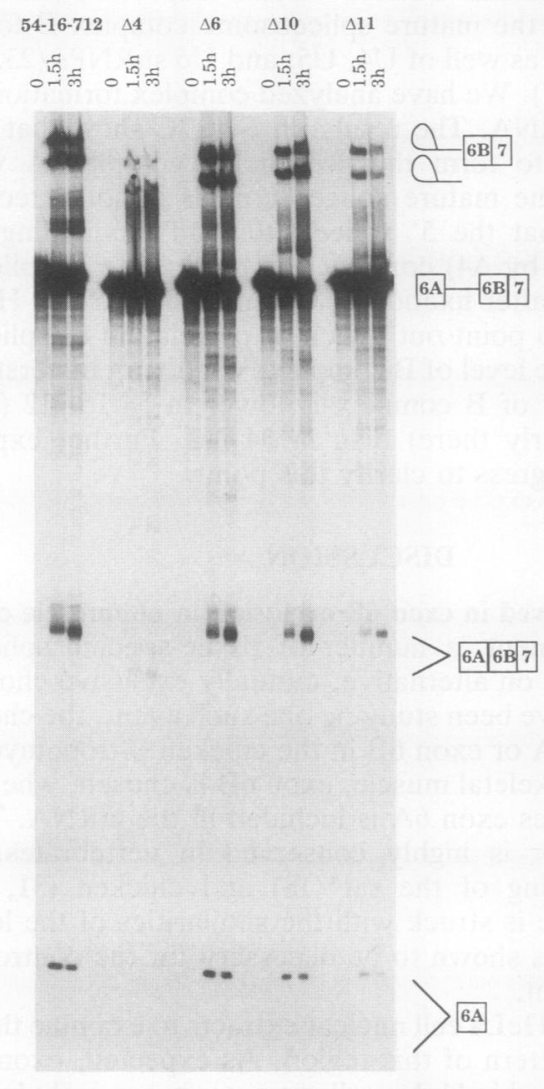

B

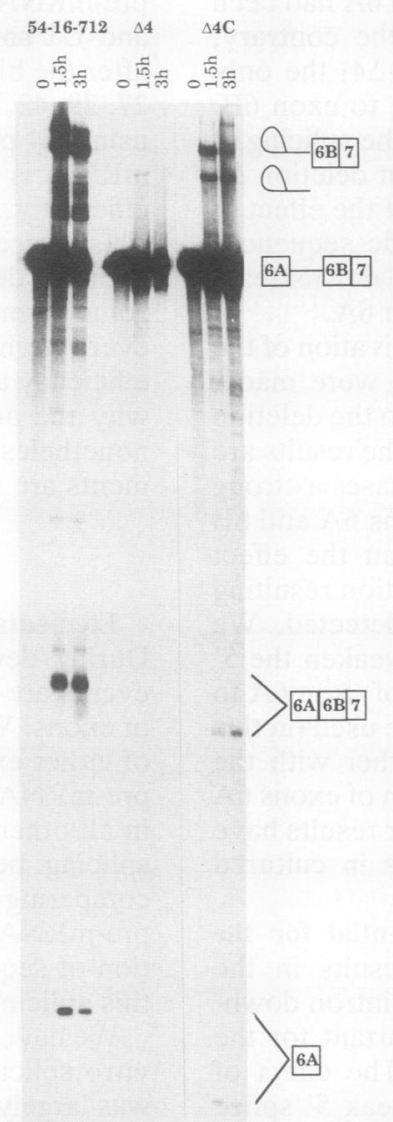

C

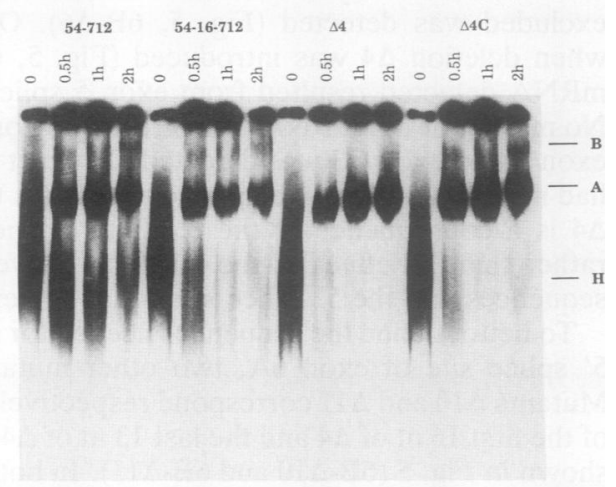

FIG. 7. (A) Sequences defined by $\Delta 4$ are essential for the recognition of the exon $6 A{ }^{\prime}$ ' splice site. The DNA templates used for in vitro transcription with SP6 polymerase contain the mutations that activate exon $6 B$ in HeLa nuclear extracts $(54-16-712)$. $\Delta 4, \Delta 6, \Delta 10$, and $\Delta 11$ correspond to 54-16-712 with the deletions in the intron shown in Fig. 6. The transcripts were incubated under splicing conditions for the indicated times, and products were separated in a $6 \%$ denaturing polyacrylamide gel. The structures of the different bands are indicated to the right of the autoradiogram. The different size of exon $6 \mathrm{~A}$ in $\Delta 4$ is due to the different polylinker sequence following the SP6 promoter in this construction (see Materials and Methods). (B) A consensus sequence in the $5^{\prime}$ splice site following exon $6 \mathrm{~A}$ does not fully compensate for the inhibitory effect of mutation $\Delta 4$. Transcripts $54-16-712, \Delta 4$, and $\Delta 4 \mathrm{C}$ were spliced and the products were separated as described above. The different size of exon $6 \mathrm{~A}$ from $\Delta 4 \mathrm{C}$ when compared with exon $6 \mathrm{~A}$ from 54-16-712 is due to the different polylinker sequence following the SP6 promoter (see Materials and Methods). (C) Analysis by native gel electrophoresis of spliceosome assembly. Transcripts 54-712, 54-16-712, $\Delta 4$, and $\Delta 4 \mathrm{C}$ were incubated under splicing conditions for the indicated times. Samples were directly loaded in a $4 \%$ polyacrylamide gel. H, nonspecific complex; A, prespliceosome complex; B, mature spliceosome.

exon 6B inhibit splicing by a mechanism other than basepairing with the sequences in the intron downstream of exon 6B (stem III).

One of the questions we asked here was whether or not inhibition of IVS $A B$ splicing could be attributed to the above-mentioned RNA structures. Two sets of experiments presented in this study strongly support a negative role, not linked to the secondary structure, for the intron sequences between exons $6 \mathrm{~A}$ and $6 \mathrm{~B}$ in the splicing of this intron. First, these sequences are capable of acting as a negative element when placed at the $3^{\prime}$ end of IVS 1 of $\beta$-globin, completely inhibiting splicing of globin exon 1 to exon 2 . This region does not inhibit by sequestering a limiting constitutive splicing factor, since preincubation of a HeLa nuclear extract with an excess of IVS AB mRNA does not inhibit $\beta$-globin splicing (data not shown). Second, we have destroyed stems II and III, leaving IVS AB intact, by fusing exon 6B to exon 7. The experiments shown in Fig. 3B show that the elimination of stems II and III does not activate IVS AB splicing. This result agrees with in vivo experiments in which stems II and III have been altered in their distal arms (in IVS B7). Such alterations did not increase exon 6B choice, either in the chicken pre-mRNA (31) or the rat pre-mRNA (18).

How then, do the sequences at the $3^{\prime}$ end of IVS AB inhibit splicing of this intron in HeLa cell extracts? It is clear that this inhibitory reaction is complex. The inhibition can be partially overcome by various substitutions of heterologous sequences in different parts of the $3^{\prime}$ half of the intron. Replacing $60 \mathrm{nt}$ in the middle of the polypyrimidine stretch region with pBR322 sequences stimulates the splicing reaction. However, we can leave the 60 -nt pyrimidine stretch intact and activate the splicing reaction by substitution of the last $18 \mathrm{nt}$ of the IVS AB with the last $18 \mathrm{nt}$ of the $\beta$-globin intron 1. The multiparameter nature of IVS $A B$ inhibition probably explains why inhibition of $\beta$-globin splicing can be partially overcome by increasing the concentration of constitutive splicing factors, whereas the homologous inhibition cannot be overcome under such conditions. Whether the inhibition is the result of the interaction of these sequences with a trans-acting factor from the HeLa cell extract (which 
would not exist in muscle cells) or is modulated by changes in the level of ubiquitous splicing factors needs to be determined. In any case the factor should be able to interact simultaneously with more than one site. Alternatively, several factors will bind to different sites, and the inhibition will be the result of their cooperative effect.

The results presented in this study also show an important role for exon $6 B$ sequences in the inhibition of IVS AB. In the chimeric $\beta$-globin constructs, when the first $20 \mathrm{nt}$ of exon 6B substitute for the first $12 \mathrm{nt}$ of exon 2 of $\beta$-globin, the pBR322 substitution leads to less efficient restoration of splicing. In particular, the second splicing reaction seems to depend on eliminating exon $6 \mathrm{~B}$ sequences. In agreement with these results, maximum activation of the splicing reaction between exons 5 or $6 \mathrm{~A}$ to $6 \mathrm{~B}$ is produced only after mutation of both intron (IVS $A B$ ) sequences and exon 6B sequences (Fig. 3B and 5).

Finally, the negative elements in the intron upstream of exon $6 \mathrm{~B}$ as well as in exon $6 \mathrm{~B}$ will inhibit the splicing of the intron downstream only when placed in the proper context. When placed upstream of an exon 6B-7 pre-mRNA, it inhibits 6B-7 splicing (8) in a structure-dependent manner. When placed upstream of the $\beta$-globin exon 1-exon 2 construct, it has no inhibitory effect (data not shown).

It is possible that a complex regulation that involves structural and nonstructural elements is responsible for exon $6 \mathrm{~B}$ repression in nonmuscle cells. First, the formation of a secondary structure around exon $6 \mathrm{~B}$ inhibits the splicing reaction between exons $6 \mathrm{~B}$ and 7 . Second, cis elements in exon $6 \mathrm{~B}$ and the intron upstream are critical for repressing the splicing of exon 5 or $6 \mathrm{~A}$ to $6 \mathrm{~B}$ by a mechanism independent of their participation in a secondary structure around exon 6B.

Role of intron sequences in exon $6 \mathrm{~A}$ selection. Transfection assays with the rat and chicken $\beta$-tropomyosin genes show variable proportions of mRNAs in which the two mutually exclusive exons are spliced together. For the wild-type pre-mRNA this type of splicing is not seen, but introduction of mutations that induce partial activation of exon $6 \mathrm{~B}$ in nonmuscle or undifferentiated muscle cells increases this type of splicing. Thus, mutually exclusive splicing in this region is different from that seen in exons 2 and 3 of the $\alpha$-tropomyosin pre-mRNA in which the two exons are unable to be spliced together because of the proximity of the branch point to the $5^{\prime}$ splice site. The results in Fig. 3 show that a pre-mRNA containing exons $6 \mathrm{~A}$ and $6 \mathrm{~B}$ and the mutations inducing activation of exon $6 \mathrm{~B}$ in nonmuscle cells is efficiently spliced in HeLa nuclear extracts.

The question of why these two exons are never spliced together in any cell type remains. Competition between splice sites has been shown to play an important role in splice site choice. In the case of the $\alpha$-tropomyosin gene, it has been shown that the exclusion of exon 2 (muscle specific) in nonmuscle cells is determined by the competition between the branch point and polypyrimidine tract elements of exons 2 and 3 . Exon 3 is chosen over exon 2 since the upstream intron has an extensive polypyrimidine tract and a strong, consensus, branch point sequence.

Competition between $3^{\prime}$ and $5^{\prime}$ splice sites has been proposed to play an important role in vivo in exon choice in the chicken $\beta$-tropomyosin gene. Replacing the branch point and following $30 \mathrm{nt}$ upstream of exon $6 \mathrm{~A}$ with the corresponding region upstream of exon $6 \mathrm{~B}$ increases the use of exon 6A in myotubes (differentiated muscle cells) (31). Mutation of the exon 6A $5^{\prime}$ splice site to a consensus sequence leads to an enhanced expression of exon $6 \mathrm{~A}$ in myotubes. This competition, although important, cannot be the only element involved in exon $6 \mathrm{~A}$ exclusion, since mutations activating exon $6 \mathrm{~B}$ are not sufficient to produce total exclusion of exon $6 \mathrm{~A}$ in myoblasts. In fact, mutations that result in the use of exon $6 \mathrm{~B}$ in $\mathrm{HeLa}$ cell extracts do not automatically lead to exclusion of exon $6 \mathrm{~A}$. This suggests that a mechanism for the nonutilization of exon $6 \mathrm{~A}$ may exist in skeletal muscle cells. One possibility is that nonmuscle cells contain a factor which is required for exon $6 \mathrm{~A}$ inclusion and that this factor could be independent of the mechanism by which exon $6 \mathrm{~B}$ is excluded in such cells. The results of the experiments presented in Fig. 5 and 7 are compatible with this idea. Splicing of the IVS AB intron, with or without the cis competition between exons 5 and $6 \mathrm{~A}$, depends on the presence of the sequence defined by the $\Delta 4$ mutations. Even when the 3 ' end of the IVS AB intron is activated for IVS AB splicing, the negative effect of the $\Delta 4$ mutation is epistatic to the positive effects of the 54 and 16 mutations. Mutation $\Delta 4$ allows formation of the presplicing complex, but spliceosome complex formation is blocked (Fig. 7C). It is interesting to notice that $\Delta 4$ and the two halves of this deletion, $\Delta 10$ and $\Delta 11$, are all able to induce exclusion of exon $6 \mathrm{~A}$ in a pre-mRNA containing exons 5, 6A, and $6 \mathrm{~B}$. On the contrary, in the absence of competition and by use of a pre-mRNA containing only exons $6 \mathrm{~A}$ and $6 \mathrm{~B}$, deletions $\Delta 4$ and $\Delta 11$ produce a strong inhibition of the splicing reaction, whereas deletion $\Delta 10$ has almost no effect. Deletion of the sequences corresponding to mutants $\Delta 10$ and $\Delta 11$ are both able to weaken the use of the exon $6 A^{\prime} 5^{\prime}$ splice site, but the $\Delta 10$ sequences are only important if a competitor $5^{\prime}$ splice site is available.

The sequence of the exon $6 \mathrm{~A}^{\prime}$ ' splice site diverges in three nucleotides from the consensus sequence GUA CUG. It is possible that a poor $5^{\prime}$ splice site could be activated by the presence of other elements near this site. We have changed the exon $6 \mathrm{~A} 5^{\prime}$ splice site into a consensus site. Surprisingly, even with a consensus site, the $\Delta 4$ deletion somewhat inhibits 6A-6B splicing (Fig. 7B). These results favor the hypothesis that sequences in the intron downstream of exon $6 \mathrm{~A}$ allow the recognition of the exon $6 \mathrm{~A} 5^{\prime}$ splice site by interacting with factors in trans. In vivo results show that deletion $\Delta 4$ induces skipping of exon $6 \mathrm{~A}$ in myoblasts but not in myotubes, suggesting a cell-specific role for these sequences in the utilization of exon $6 \mathrm{~A}$ (3a). Furthermore, preliminary results with gel retardation assays show that $\Delta 4$ sequences specifically recognize a protein present in HeLa nuclear extracts. Further experiments are in progress to identify and characterize this protein. We believe that the mutually exclusive splicing of the chicken $\beta$-tropomyosin exons $6 \mathrm{~A}$ and $6 \mathrm{~B}$ as well as their specific selection is regulated in trans. Whether this is the result of tissuespecific factors or quantitative differences of constitutive splicing factors is yet to be determined.

\section{ACKNOWLEDGMENTS}

We thank P. Sirand-Pugnet, A. Expert-Besançon, and J. Marie for carefully reading the manuscript as well as for helpful discussions.

This work was supported by the CNRS, INSERM (contrat externe 881002), Association Française contre la Myopathie (AFM), and Association pour la Recherche sur le Cancer (ARC). M.E.G. was supported by contract SC1-0242 from the Commission of the European Communities.

\section{REFERENCES}

1. Abmayr, S. M., R. Reed, and T. Maniatis. 1988. Identification of a functional mammalian spliceosome containing unspliced premRNA. Proc. Natl. Acad. Sci. USA 85:7216-7220. 
2. Aebi, M., H. Hornig, and C. Weissman. 1987. 5' cleavage site in eukaryotic pre-mRNA splicing is determined by the overall $5^{\prime}$ splice region, not by the conserved 5' GU. Cell 50:237-246.

3. Baker, B. S. 1989. Sex in flies: the splice of life. Nature (London) 340:521-524.

3a.Balvay, L., D. Libri, M. Gallego, and M. Y. Fiszman. 1992. Intronic sequence with both negative and positive effects on the regulation of alternative transcripts of the chicken $\beta$ tropomyosin transcirpts. Nucleic Acids Res. 20:3987-3992.

4. Bingham, P. M., T.-B. Chou, I. Mims, and Z. Zachar. 1988. On/off regulation of gene expression at the level of splicing. Trends Genet. 4:134-140.

5. Black, D. L. 1991. Does steric interference between splice sites block the splicing of a short c-src neuron-specific exon in non-neuronal cells? Genes Dev. 5:389-402.

6. Brody, E., and J. Abelson. 1985. The "spliceosome": yeast pre-messenger RNA associates with a $40 \mathrm{~S}$ complex in a splicingdependent reaction. Science 228:963-967.

7. Clouet-d'Orval, B., Y. d'Aubenton-Carafa, J. Marie, and E. Brody. 1991. Determination of an RNA structure involved in splicing inhibition of a muscle specific exon. J. Mol. Biol. 221:837-856.

8. Clouet-d'Orval, B., Y. d'Aubenton-Carafa, P. Sirand-Pugnet, M. Gallego, E. Brody, and J. Marie. 1991. RNA structure represses utilization of a muscle specific exon in Hela cell nuclear extracts. Science 252:1823-1828.

9. Cooper, T. A., and C. P. Ordahl. 1989. Nucleotide substitutions within the cardiac troponin $\mathrm{T}$ alternative exon disrupt premRNA alternative splicing. Nucleic Acids Res. 17:7905-7921.

10. Dignam, J. D., R. R. Lebovitz, and R. G. Roeder. 1983. Accurate transcription initiation by RNA polymerase II in a soluble extract from isolated mammalian nuclei. Nucleic Acids Res. 11:1475-1489.

11. Domenjoud, L., H. Gallinaro, L. Kister, S. Meyer, and M. Jacob. 1991. Identification of a specific exon sequence that is a major determinant in the selection between a natural and a cryptic 5' splice site. Mol. Cell. Biol. 11:4581-4590.

12. Frendewey, D., and W. Keller. 1985. Stepwise assembly of a pre-mRNA splicing complex requires U-snRNP and specific intron sequences. Cell 42:355-367.

13. Fu, X. Y., H. Ge, and J. L. Manley. 1988. The role of the polypyrimidine stretch at the SV40 early pre-mRNA 3 ' splice site in alternative splicing. EMBO J. 7:809-817.

14. Fu, X. Y., and J. L. Manley. 1987. Factors influencing alternative splice site utilization in vivo. Mol. Cell. Biol. 7:738-748.

15. Ge, H., and J. L. Manley. 1990. A protein factor, ASF, controls cell-specific alternative splicing of SV40 early pre-mRNA in vitro. Cell 62:25-34.

16. Goux-Pelletan, M., D. Libri, Y. D'Aubenton-Carafa, M. Fiszman, E. Brody, and J. Marie. 1990. In vitro splicing of mutually exclusive exons from the chicken beta-tropomyosin gene: role of the branch point location and very long pyrimidine stretch. EMBO J. 9:241-249.

17. Grabowski, P. J., S. R. Seiler, and P. A. Sharp. 1985. A multicomponent complex is involved in the splicing of messenger RNA precursors. Cell 42:345-353.

18. Guo, W., G. J. Mulligan, S. Wormsley, and D. M. Helfman. 1991. Alternative splicing of beta-tropomyosin pre-messenger RNA-cis-acting elements and cellular factors that block the use of a skeletal muscle exon in nonmuscle cells. Genes Dev. 5:2096-2107.

19. Hampson, R. K., L. La Follette, and F. M. Rottman. 1989. Alternative processing of bovine growth hormone mRNA is influenced by downstream exon sequences. Mol. Cell. Biol. 9:1604-1610.

20. Helfman, D. M., and W. M. Ricci. 1989. Branch point selection in alternative splicing of tropomyosin pre-mRNA. Nucleic Acids Res. 17:5633-5650.

21. Helfman, D. M., W. M. Ricci, and L. A. Finn. 1988. Alternative splicing of tropomyosin pre-mRNAs in vitro and in vivo. Genes Dev. 2:1627-1638.

22. Helfman, D. M., R. F. Roscigno, G. J. Mulligan, L. A. Finn, and K. S. Weber. 1990. Identification of two distinct intron elements involved in alternative splicing of $\beta$ tropomyosin pre-mRNA. Genes Dev. 4:98-110.

23. Konarska, M. M., and P. A. Sharp. 1986. Electrophoretic separation of complexes involved in the splicing of precursors to mRNA. Cell 46:845-855.

24. Konarska, M. M., and P. A. Sharp. 1987. Interaction between small nuclear ribonucleoprotein particles in formation of spliceosomes. Cell 49:763-774.

25. Krainer, A. R., G. C. Conway, and D. Kozak. 1990. The essential pre-mRNA splicing factor SF2 influences 5' splice site selection by activating proximal sites. Cell 62:35-42.

26. Krainer, A. R., G. C. Conway, and D. Kozak. 1990. Purification and characterization of pre-mRNA splicing factor SF2 from Hela cells. Genes Dev. 4:1158-1171.

27. Kramer, A. 1988. Presplicing complex formation requires two proteins and U2 snRNP. Genes Dev. 2:1155-1167.

28. Kuo, H.-C., F.-U. H. Nasim, and P. J. Grabowski. 1991. Control of alternative splicing by the differential binding of U1 small nuclear ribonucleoprotein particle. Science 251:1045-1050.

29. Lamond, A. I., M. M. Konarska, and P. A. Sharp. 1987. A mutational analysis of spliceosome assembly: evidence for splice site collaboration during spliceosome formation. Genes Dev. 1:532-543.

30. Lear, A. L., L. P. Eperon, I. M. Wheatley, and I. C. Eperon. 1990 . Hierarchy for $5^{\prime}$ splice site preference determined in vivo. J. Mol. Biol. 211:103-115.

31. Libri, D., L. Balvay, and M. Y. Fiszman. 1992. In vivo splicing of the $\beta$ tropomyosin pre-mRNA: a role for branch point and donor site competition. Mol. Cell. Biol. 12:3204-3215.

32. Libri, D., M. Goux-Pelletan, E. Brody, and M. Fiszman. 1990. Exon as well as intron sequences are cis regulating elements for the mutually exclusive alternative splicing of the $\beta$-tropomyosin gene. Mol. Cell. Biol. 10:5036-5046.

33. Libri, D., M. Lemonnier, T. Meinnel, and M. Y. Fiszman. 1989. A single gene codes for the $\beta$ subunit of smooth and skeletal muscle tropomyosin in the chicken. J. Biol. Chem. 264:29352944.

34. Libri, D., A. Piseri, and M. Fiszman. 1991. Tissue specific splicing in vivo of the $\beta$ tropomyosin gene: dependence on an RNA secondary structure. Science 252:1842-1845.

35. Maniatis, T. 1991. Mechanisms of alternative pre m-RNA splicing. Science 251:33-34.

36. Maniatis, T., E. F. Fritsch, and J. Sambrook. 1982. Molecular cloning: a laboratory manual. Cold Spring Harbor Laboratory, Cold Spring Harbor, N.Y.

37. Mardon, H. J., G. Sebastio, and F. E. Baralle. 1987. A role for exon sequences in alternative splicing of the human fibronectin gene. Nucleic Acids Res. 15:7725-7733.

38. Mullen, M. P., C. W. J. Smith, J. G. Patton, and B. NadalGinard. 1991. $\alpha$-Tropomyosin mutually exclusive exon selection: competition between branch point/polypyrimidine tracts determines default exon choice. Genes Dev. 5:642-655.

39. Nelson, K. K., and M. R. Green. 1988. Splice site selection and ribonucleoprotein complex assembly during in vitro pre-mRNA splicing. Genes Dev. 2:319-329.

40. Noble, J. C. S., C. Prives, and J. L. Manley. 1988. Alternative splicing of SV40 early pre-mRNA is determined by branch site selection. Genes Dev. 2:1460-1475.

41. Peterson, M. L., and R. P. Perry. 1989. The regulated production of $\mu_{\mathrm{m}}$ and $\mu_{\mathrm{s}} \mathrm{mRNA}$ is dependent on the relative efficiencies of $\mu_{s}$ poly(A) site usage and the C $\mu$ 4-to-M1 splice. Mol. Cell. Biol. 9:726-738.

42. Pikielny, C. W., B. C. Rymond, and M. Rosbash. 1986. Electrophoresis of ribonucleoproteins reveals an ordered assembly pathway of yeast splicing complexes. Nature (London) 324:341345.

43. Reed, R., and T. Maniatis. 1986. A role for exon sequences and splice site proximity in splice site selection. Cell 46:681-690.

44. Reed, R., and T. Maniatis. 1988. The role of mammalian branchpoint sequence in pre-mRNA splicing. Genes Dev. 2:1268-1276

45. Ruskin, B., and M. R. Green. 1985. An RNA processing activity that debranches RNA lariats. Science 229:135-140. 
46. Ruskin, B., A. R. Krainer, T. Maniatis, and M. R. Green. 1984. Excision of an intact intron as a novel lariat structure during pre-mRNA splicing in vitro. Cell 38:317-331.

47. Ruskin, B., P. D. Zamore, and M. R. Green. 1988. A factor, $\mathrm{U} 2 \mathrm{AF}$, is required for $\mathrm{U} 2 \mathrm{snRNP}$ binding and splicing complex assembly. Cell 52:207-219.

48. Ryner, L. C., and B. S. Baker. 1991. Regulation of doublesex pre-messenger RNA processing occurs by 3 '-splice site activation. Genes Dev. 5:2071-2085.

49. Siebel, C. W., and D. Rio. 1990. Regulated splicing of the Drosophila $P$ transposable element third intron in vitro: somatic repression. Science 248:1200-1208.

50. Smith, C. W. J., and B. Nadal-Ginard. 1989. Mutually exclusive splicing of alfa tropomyosin exons enforced by an unusual lariat branch point location: implications for constitutive splicing. Cell 56:749-758.

51. Smith, C. W. J., J. G. Patton, and B. Nadal-Ginard. 1989. Alternative splicing in the control of gene expression. Annu. Rev. Genet. 23:527-577.

52. Streuli, M., and H. Saito. 1989. Regulation of tissue specific alternative splicing: exon-specific cis-elements govern the splicing of leukocyte common antigen pre-mRNA. EMBO J. 8:787-796.

53. Wu, J., and J. L. Manley. 1989. Mammalian pre-mRNA branch site selection by U2 sn RNP involves base pairing. Genes Dev. 3:1553-1561.

54. Zachar, Z., T.-B. Chou, and P. Bingham. 1987. Evidence that a regulatory gene autoregulates splicing of its transcript. EMBO J. 6:4105-4111.

55. Zhuang, Y., H. Leung, and A. Weiner. 1987. The natural 5' splice site of simian virus 40 large $T$ antigen can be improved by increasing the base complementarity to U1 RNA. Mol. Cell. Biol. 7:3018-3020.

56. Zhuang, Y., and A. Weiner. 1989. A compensatory base change in human U2 snRNA can suppress a branch site mutation. Genes Dev. 3:1545-1552.

57. Zillmann, M., M. L. Zapp, and S. M. Berget. 1988. Gel electrophoretic isolation of splicing complexes containing U1 small nuclear ribonucleoprotein particles. Mol. Cell. Biol. 8:814-821. 